BRIEF

\title{
Food Insecurity and Self-Reported Hypertension Among Hispanic, Black, and White Adults in 12 States, Behavioral Risk Factor Surveillance System, 2009
}

\author{
Shalon M. Irving, PhD, MPH, CHES; Rashid S. Njai, PhD, MPH; Paul Z. Siegel, MD, MPH
}

\begin{abstract}
Suggested citation for this article: Irving SM, Njai RS, Siegel PZ. Food Insecurity and Self-Reported Hypertension Among Hispanic, Black, and White Adults in 12 States, Behavioral Risk Factor Surveillance System, 2009. Prev Chronic Dis 2014;11:140190. DOI: http://dx.doi.org/10.5888/pcd11.140190.
\end{abstract}

\section{PEER REVIEWED}

\section{Abstract}

Food insecurity is positively linked to risk of hypertension; however, it is not known whether this relationship persists after adjustment for socioeconomic position (SEP). We examined the association between food insecurity and self-reported hypertension among adults aged 35 or older $(\mathrm{N}=58,677)$ in 12 states that asked the food insecurity question in their 2009 Behavioral Risk Factor Surveillance System questionnaire. After adjusting for SEP, hypertension was more common among adults reporting food insecurity (adjusted prevalence ratio, $1.27 ; 95 \%$ confidence interval, 1.19-1.36). Our study found a positive relationship between food insecurity and hypertension after adjusting for SEP and other characteristics.

\section{Objective}

Food security is a social determinant of health characterized by availability of and access to adequate food (1). Given the number of people with economic and physical challenges to food access, food insecurity - uncertain ability to acquire adequate food - is a public health concern (2-4). Although food insecurity is associated with hypertension among low-income populations (5), it is not known whether this relationship is independent of socioeconomic position (SEP), one potential confounder. Our objective was to examine the association between food insecurity and hypertension after adjusting for SEP and other characteristics. An inde- pendent association would support the idea that alleviating food insecurity reduces hypertension without intervening on SEP.

\section{Methods}

We analyzed data from 12 states (Alabama, Arkansas, California, Hawaii, Illinois, Kansas, Louisiana, Nebraska, New Mexico, Oklahoma, South Carolina, and Wisconsin) that asked the food insecurity question in the 2009 Behavioral Risk Factor Surveillance System (BRFSS). BRFSS is a state-based, random-digit-dialed telephone survey of the civilian, noninstitutionalized adult US population. The sample was restricted to Hispanic, non-Hispanic black, and non-Hispanic white adults aged 35 or older $(\mathrm{N}=$ $58,677)$ because of the low prevalence of hypertension among younger adults (6) and insufficient statistical power for stratified analyses among other racial/ethnic groups.

Food insecurity was measured by asking, "How often in the past 12 months would you say you were worried or stressed about having enough money to buy nutritious meals?" Respondents answering "always," "usually," or "sometimes" were categorized as insecure; those answering "rarely" or "never" were categorized as secure. The food insecurity item, which measures stress-related food insecurity, was validated by the US Department of Agriculture's Current Population Survey Food Security Supplement, a 10item food security scale $(r=.71, P<.001)$ (M. Nord, PhD, MS, written communication, May 2012).

Hypertension was measured by asking, "Have you ever been told by a doctor, nurse, or health professional that you have high blood pressure?" Respondents answering yes were categorized as having hypertension; those answering no or indicating borderline high blood pressure or prehypertension were categorized as nonhypertensive. Data on women reporting pregnancy-induced hypertension were excluded from analysis (6). 
SEP was measured by level of education ( $<$ high school, high school graduate or GED [general education development], or any college) and a household's relationship to the federal poverty level (ie, income as a percentage of the federal poverty level, or incometo-poverty ratio).

Significant differences between subgroups were assessed using $\chi^{2}$ tests for categorical variables and Cochran-Mantel-Haenszel trend tests for ordinal variables. Prevalence ratios (PRs) and 95\% confidence intervals (CIs) for the association between food insecurity and hypertension were calculated using logistic regression. PRs were adjusted for SEP and other potential confounders between food insecurity and hypertension: age, sex, race/ethnicity, education, percentage federal poverty level, health insurance coverage, marital status, and current smoking status (6). Analyses used SAScallable SUDAAN (SAS version 9.3, SAS Institute Inc; SUDAAN, RTI International) to account for the BRFSS complex sampling design; predicted marginals were used to produce PR estimates (7).

\section{Results}

Of the 58,677 adults included in the analysis, 47,734 (81.4\%) were non-Hispanic white, 36,757 (62.6\%) were women, and 21,248 $(36.2 \%)$ were 65 or older. The prevalence of food insecurity was $17.3 \%$ (95\% CI, $16.5 \%-18.1 \%)$ overall and varied among racial/ ethnic groups - highest among Hispanics (30.3\%; 95\% CI, $27.1 \%-33.7 \%)$, lower among non-Hispanic blacks (26.7\%; $95 \%$ CI, 24.5\%-29.0\%), and lowest among non-Hispanic whites (13.0\%; 95\% CI, 12.4\%-13.6\%) (Table 1). Prevalence of food insecurity also varied by age and sex: older adults and men were less likely to report food insecurity (both $P<.001$ ). The overall prevalence of self-reported hypertension was $37.4 \%$ (95\% CI, $36.5 \%-38.3 \%$ ); when stratified by race/ethnicity, the prevalence of hypertension was highest among non-Hispanic blacks (52.3\%; 95\% CI, 49.6\%-55.0\%), lower among non-Hispanic whites (36.4\%; 95\% CI, 35.6\%-37.2\%), and lowest among Hispanics $(33.7 \%$; $95 \%$ CI, 30.7\%-36.8\%). Prevalence of hypertension varied by age $(P<.001)$; however, we found no difference by sex $(P$ $=.09$ ).

In the unadjusted model for the overall sample, food insecurity was associated with an increased likelihood of reporting hypertension (PR, 1.22; 95\% CI, 1.15-1.30) (Table 2). This association remained after adjusting for age, sex, race/ethnicity, education, percentage federal poverty level, health insurance coverage, marital status, and current smoking status (adjusted PR, 1.27; 95\% CI, 1.19-1.36).

\section{Discussion}

Our study shows a positive relationship between stress associated with accessing adequate food - one dimension of food insecurity - and hypertension, after adjustment for education, percentage federal poverty level, and other characteristics. Our findings suggest that food insecurity is associated with hypertension regardless of demographic group, thus, reinforcing previous research (5). Action to remove barriers to accessing affordable, healthful foods could decrease the prevalence of hypertension without directly ameliorating other factors. Thus, food security is an actionable social determinant with potential for broad public health impact $(2,4,8,9)$. Increased access to affordable healthful foods can improve food environments and thus promote more healthful default decisions and improve healthy eating $(8,10)$. Healthier lifestyles create the potential for reduced risk of hypertension and other chronic diseases (3).

The BRFSS has some limitations. BRFSS data are self-reported and cross-sectional and thus are subject to issues inherent in selfreported data and do not allow explorations of causality. Second, the BRFSS assesses lifetime prevalence of hypertension and 12month prevalence of food insecurity. Thus, if food security occurred more than 12 months before the survey, survey data may underestimate the association between hypertension and food insecurity. Finally, the generalizability of the findings is limited because only 12 states used the food security question in their BRFSS. However, our study sample (adults aged 35 or older who were asked the food insecurity question) represents $30 \%$ of the US population aged 35 or older (11). Despite these limitations, the validated single-item BRFSS food security question can be used to improve efforts to monitor prevalence and assess the effectiveness of interventions.

Addressing the relationship between food insecurity and hypertension or other cardiovascular diseases enhances our understanding of effects associated with the stress of attempting to meet one's basic needs. Whether food insecurity is caused by limited socioeconomic access, physiological stress, or overconsumption of nutrient-poor, high-sodium food (4), our findings underscore the importance of examining food insecurity further in the context of chronic disease prevention.

\section{Acknowledgments}

No financial support was received for this work.

\footnotetext{
The opinions expressed by authors contributing to this journal do not necessarily reflect the opinions of the U.S. Department of Health and Human Services, the Public Health Service, the Centers for Disease Control and Prevention, or the authors' affiliated institutions.
} 


\section{Author Information}

Corresponding Author: Shalon M. Irving, PhD, MPH, CHES, Research, Surveillance and Evaluation Branch, Division of Community Health, National Center for Chronic Disease Prevention and Health Promotion, Centers for Disease Control and Prevention, 4770 Buford Hwy NE, MS F-73, Atlanta, GA 30341. Telephone: 770-488-5765. E-mail: SIrving@cdc.gov.

Author Affiliations: Rashid S. Njai, Paul Z. Siegel, Centers for Disease Control and Prevention, Atlanta, Georgia.

\section{References}

1. Hamm MW, Bellows AC. Community food security: background and future directions. J Nutr Educ Behav 2003; 35(1):37-43.

2. Coleman-Jensen A, Nord M, Singh A.Household food security in the United States, 2012. US Department of Agriculture, Economic Research Service; 2013.

3. National Prevention Council. National prevention council action plan: implementing the national prevention strategy. Washington (DC): US Department of Health and Human Services, Office of the Surgeon General, 2012.

4. Seligman HK, Schillinger D. Hunger and socioeconomic disparities in chronic disease. N Engl J Med 2010;363(1):6-9.

5. Seligman HK, Laraia BA, Kushel MB. Food insecurity is associated with chronic disease among low-income NHANES participants. J Nutr 2010;140(2):304-10.

6. Gillespie CD, Hurvitz KA. Prevalence of hypertension and controlled hypertension - United States, 2007-2010. MMWR Surveill Summ 2013;62(3):144-8.

7. Bieler GS, Brown GG, Williams RL, Brogan DJ. Estimating model-adjusted risks, risk differences, and risk ratios from complex survey data. Am J Epidemiol 2010;171(5):618-23.

8. Frieden TR. A framework for public health action: the health impact pyramid. Am J Public Health 2010;100(4):590-5.

9. Chilton M, Rose D. A rights-based approach to food insecurity in the United States. Am J Public Health 2009;99(7):1203-11.

10. Young CR, Aquilante JL, Solomon S, Colby L, Kawinzi MA, Uy N, et al. Improving fruit and vegetable consumption among low-income customers at farmers markets: Philly Food Bucks, Philadelphia, Pennsylvania, 2011. Prev Chronic Dis 2013; 10:E166.

11. US Census Bureau. Census summary: 2000: Census 2000 profile. www.census.gov/prod/2002pubs/c2kprof00-us.pdf. Accessed February 3, 2014.

The opinions expressed by authors contributing to this journal do not necessarily reflect the opinions of the U.S. Department of Health and Human Services, the Public Health Service, the Centers for Disease Control and Prevention, or the authors' affiliated institutions. 


\section{Tables}

Table 1. Prevalence of Food Insecurity and Hypertension, by Selected Sociodemographic Characteristics Among Hispanic, NonHispanic Black, and Non-Hispanic White Adults in 12 States $^{\mathrm{a}}(\mathrm{N}=58,677)$, Behavioral Risk Factor Surveillance System, 2009

\begin{tabular}{|c|c|c|c|c|c|}
\hline \multirow[b]{2}{*}{ Sociodemographic Characteristic } & \multirow[b]{2}{*}{$n^{d}$} & \multicolumn{2}{|c|}{ Food Insecurity ${ }^{b}$} & \multicolumn{2}{|c|}{ Self-Reported Hypertensionc } \\
\hline & & $\begin{array}{c}\text { Prevalence, } \% \text { (95\% } \\
\mathrm{Cl})\end{array}$ & $P$ Value ${ }^{\mathrm{e}}$ & Prevalence, \% (95\% Cl) & $P$ Value ${ }^{\mathrm{e}}$ \\
\hline Overall & 58,677 & $17.3(16.5-18.1)$ & - & $37.4(36.5-38.3)$ & - \\
\hline \multicolumn{6}{|l|}{ Race/ethnicity } \\
\hline Hispanic & 4,067 & $30.3(27.1-33.7)$ & \multirow{3}{*}{$<.001$} & $33.7(30.7-36.8)$ & \multirow{3}{*}{$<.001$} \\
\hline Non-Hispanic black & 6,876 & $26.7(24.5-29.0)$ & & $52.3(49.6-55.0)$ & \\
\hline Non-Hispanic white & 47,734 & $13.0(12.4-13.6)$ & & $36.4(35.6-37.2)$ & \\
\hline \multicolumn{6}{|l|}{ Sex } \\
\hline Male & 21,920 & $14.5(13.3-15.7)$ & \multirow{2}{*}{$<.001$} & $38.2(36.8-39.6)$ & \multirow{2}{*}{.09} \\
\hline Female & 36,757 & $19.8(18.8-20.8)$ & & $36.7(35.6-37.7)$ & \\
\hline \multicolumn{6}{|l|}{ Age, y } \\
\hline $35-44$ & 8,846 & $22.2(20.4-24.0)$ & \multirow{4}{*}{$<.001$} & $19.8(18.2-21.5)$ & \multirow{4}{*}{$<.001$} \\
\hline $45-54$ & 13,619 & $20.3(18.8-21.9)$ & & $30.8(29.1-32.5)$ & \\
\hline $55-64$ & 14,964 & $15.8(14.4-17.4)$ & & $45.1(43.2-46.9)$ & \\
\hline$\geq 65$ & 21,248 & $9.4(8.6-10.3)$ & & $59.0(57.5-60.5)$ & \\
\hline \multicolumn{6}{|l|}{ Marital status } \\
\hline Married/unmarried couple & 34,423 & $14.2(13.3-15.1)$ & \multirow{4}{*}{$<.001$} & $33.6(32.6-34.7)$ & \multirow{4}{*}{$<.001$} \\
\hline Widowed & 9,625 & $15.8(14.2-17.5)$ & & $61.1(58.9-63.2)$ & \\
\hline Divorced/separated & 9,832 & $29.8(27.7-31.9)$ & & $41.5(39.3-43.8)$ & \\
\hline Never married & 4,619 & $25.9(22.5-29.6)$ & & $39.1(35.6-42.6)$ & \\
\hline \multicolumn{6}{|l|}{ Education } \\
\hline$<$ High school & 5,792 & $36.0(32.4-39.7)$ & \multirow{3}{*}{$<.001$} & $44.1(40.8-47.4)$ & \multirow{3}{*}{$<.001$} \\
\hline High school graduate/GED ${ }^{f}$ & 17,855 & $20.3(19.0-21.8)$ & & $41.6(40.0-43.2)$ & \\
\hline Any college & 34,841 & $12.4(11.7-13.1)$ & & $34.2(33.2-35.2)$ & \\
\hline \multicolumn{6}{|l|}{$\%$ Federal poverty level } \\
\hline$<130$ & 9,374 & $42.2(39.5-44.9)$ & $<.001$ & $45.1(42.5-47.6)$ & $<.001$ \\
\hline
\end{tabular}

Abbreviation: $\mathrm{Cl}$, confidence interval.

a Alabama, Arkansas, California, Hawaii, Illinois, Kansas, Louisiana, Nebraska, New Mexico, Oklahoma, South Carolina, and Wisconsin.

b Defined as a response of "always," "usually," or "sometimes" to the question "How often in the past 12 months would you say you were worried or stressed about having enough money to buy nutritious meals?"

${ }^{c}$ Defined as a response of yes to the question "Have you ever been told by a doctor, nurse, or other health professional that you have high blood pressure?"

d Sample sizes may vary because some respondents did not answer all questions.

e $P$ values for race/ethnicity, sex, marital status, health insurance coverage, and current smoking status obtained by using $x^{2}$ tests; $P$ values for age, education, and percentage federal poverty level obtained by using Cochran-Mantel-Haenszel trend test.

${ }^{f}$ General educational development (GED) is a high school equivalency credential.

(continued on next page)

The opinions expressed by authors contributing to this journal do not necessarily reflect the opinions of the U.S. Department of Health and Human Services, the Public Health Service, the Centers for Disease Control and Prevention, or the authors' affiliated institutions. 
(continued)

Table 1. Prevalence of Food Insecurity and Hypertension, by Selected Sociodemographic Characteristics Among Hispanic, NonHispanic Black, and Non-Hispanic White Adults in 12 States $^{\mathrm{a}}(\mathrm{N}=58,677)$, Behavioral Risk Factor Surveillance System, 2009

\begin{tabular}{|c|c|c|c|c|c|}
\hline \multirow[b]{2}{*}{ Sociodemographic Characteristic } & \multirow[b]{2}{*}{$\mathrm{n}^{\mathrm{d}}$} & \multicolumn{2}{|c|}{ Food Insecurity ${ }^{b}$} & \multicolumn{2}{|c|}{ Self-Reported Hypertension ${ }^{c}$} \\
\hline & & $\begin{array}{l}\text { Prevalence, \% (95\% } \\
\text { Cl) }\end{array}$ & $P$ Value & Prevalence, \% (95\% Cl) & $P$ Value \\
\hline 130 to $<200$ & 6,147 & $25.4(22.9-28.0)$ & & $38.4(35.6-41.2)$ & \\
\hline 200 to $<400$ & 20,308 & $11.9(11.0-12.9)$ & & $33.9(32.6-35.2)$ & \\
\hline$\geq 400$ & 15,251 & $4.4(3.9-5.1)$ & & $34.6(33.2-36.0)$ & \\
\hline \multicolumn{6}{|l|}{ Health insurance coverage } \\
\hline Yes & 53,001 & $14.5(13.8-15.2)$ & \multirow{2}{*}{$<.001$} & $37.9(37.0-38.8)$ & \multirow{2}{*}{.01} \\
\hline No & 5,581 & $38.6(35.3-42.1)$ & & $33.7(30.5-37.0)$ & \\
\hline \multicolumn{6}{|l|}{ Current smoking status } \\
\hline Yes & 9,247 & $29.8(27.5-32.1)$ & \multirow{2}{*}{$<.001$} & $37.4(35.2-39.7)$ & \multirow{2}{*}{.97} \\
\hline No & 49,228 & $15.1(14.2-15.8)$ & & $37.4(36.4-38.3)$ & \\
\hline
\end{tabular}

Abbreviation: $\mathrm{Cl}$, confidence interval.

a Alabama, Arkansas, California, Hawaii, Illinois, Kansas, Louisiana, Nebraska, New Mexico, Oklahoma, South Carolina, and Wisconsin.

b Defined as a response of "always," "usually," or "sometimes" to the question "How often in the past 12 months would you say you were worried or stressed about having enough money to buy nutritious meals?"

c Defined as a response of yes to the question "Have you ever been told by a doctor, nurse, or other health professional that you have high blood pressure?"

d Sample sizes may vary because some respondents did not answer all questions.

e $P$ values for race/ethnicity, sex, marital status, health insurance coverage, and current smoking status obtained by using $x^{2}$ tests; $P$ values for age, education, and percentage federal poverty level obtained by using Cochran-Mantel-Haenszel trend test.

${ }^{f}$ General educational development (GED) is a high school equivalency credential. 
Table 2. Unadjusted and Adjusted Prevalence Ratios for the Association Between Food Insecuritya and Hypertension ${ }^{\mathrm{b}}$, by Selected Demographic Characteristics, 12 States $^{c}$, Behavioral Risk Factor Surveillance System, 2009

\begin{tabular}{|c|c|c|}
\hline Characteristic & Unadjusted Prevalence Ratio (95\% Cl) & Adjusted Prevalence Ratiod $(95 \% \mathrm{Cl})$ \\
\hline Overall & $1.22(1.15-1.30)$ & $1.27(1.19-1.36)$ \\
\hline \multicolumn{3}{|l|}{ Race/ethnicity } \\
\hline Hispanic & $1.39(1.13-1.71)$ & $1.41(1.15-1.73)$ \\
\hline Non-Hispanic black & $1.13(1.02-1.25)$ & $1.13(1.01-1.26)$ \\
\hline Non-Hispanic white & $1.17(1.11-1.25)$ & $1.26(1.19-1.34)$ \\
\hline \multicolumn{3}{|l|}{ Sex } \\
\hline Male & $1.28(1.16-1.42)$ & $1.35(1.22-1.50)$ \\
\hline Female & $1.19(1.11-1.28)$ & $1.22(1.13-1.31)$ \\
\hline \multicolumn{3}{|l|}{ Age, y } \\
\hline $35-44$ & $1.78(1.49-2.14)$ & $1.70(1.41-2.05)$ \\
\hline $45-54$ & $1.50(1.33-1.70)$ & $1.36(1.19-1.55)$ \\
\hline $55-64$ & $1.30(1.17-1.44)$ & $1.16(1.02-1.32)$ \\
\hline
\end{tabular}

Abbreviation: $\mathrm{Cl}$, confidence interval.

a Alabama, Arkansas, California, Hawaii, Illinois, Kansas, Louisiana, Nebraska, New Mexico, Oklahoma, South Carolina, and Wisconsin.

b Defined as a response of "always," "usually," or "sometimes" to the question "How often in the past 12 months would you say you were worried or stressed about having enough money to buy nutritious meals?"

'Defined as a response of yes to the question "Have you ever been told by a doctor, nurse, or other health professional that you have high blood pressure?"

$\mathrm{d}$ Adjusted for race/ethnicity, sex, age, marital status, education, percentage federal poverty level, health insurance coverage, and current smoking status.

The opinions expressed by authors contributing to this journal do not necessarily reflect the opinions of the U.S. Department of Health and Human Services, the Public Health Service, the Centers for Disease Control and Prevention, or the authors' affiliated institutions. 